Protocol design and ideas research exchange

\title{
Kids Intervention Therapy - Aquatic Environment (KITE) for babies 4 to 18 months old, by following the International Classification of Functioning (ICF): clinical trial protocol
}

\author{
${\text { Luize Bueno de } \text { Araujo }^{1} \text { (D), Tainá Ribas } \text { Mélo }^{2} \text { (D), Vera Lúcia Israel }}^{1,3}$ (D) \\ 'Universidade Federal do Paraná, Programa de Pós-Graduação em Educação Física, Curitiba, \\ PR, Brasil. \\ ${ }^{2}$ Universidade Federal do Paraná, Setor Litoral, Departamento de Saúde Coletiva, Matinhos, PR, \\ Brasil. \\ ${ }^{3}$ Universidade Federal do Paraná, Departamento de Fisioterapia, Curitiba, PR, Brasil.
}

\begin{abstract}
Introduction: the biopsychosocial (BPS) model from the perspective of the International Classification of Functioning (ICF) agrees with the current theories regarding child development. They state the interdependence between the individual's relations, environment and received stimuli. The early interventions, particularly in the aquatic environment (AE), present gaps concerning their systematization, above all in their being in accordance with the ICF. Objectives: to describe an ICF-based aquatic early intervention program, named KITE, for the neuropsychomotor development (NPMD) of typical, at-risk and/or delayed babies 4 to 18 months old. Methods: the KITE is a program systematized on the AE, centered on the family and the daycare environment; it takes place twice a week, lasting for 4 weeks, in 45- to 60-minute sessions. The assessments and interventions are systematized by following the ICF. For the main outcome on the NPMD, the Alberta Infant Motor Scale (AIMS) and the Denver Developmental Screening Test II (DDST-II) are used, and as the secondary outcome on the stimulation received, quality of life and aquatic skills, the Affordances in the Home Environment for Motor Development - Infant Scale (AHEMD-IS), the Pediatric Quality of Life Inventory (PedsQL ${ }^{\mathrm{TM}}$ ) and the Aquatic Functional Assessment Scale - Baby (AFAS Baby) are used, respectively. Conclusion: This study has presented tools for the application of a clinical trial through the KITE for the NPMD of babies, systematized and based on the BPS perspective of the ICF, and discussed according to the neuroplastic evidence of the child development.
\end{abstract}

Keywords: physiotherapy, early intervention, hydrotherapy, day care centers, international classification of functioning, disability and health.

\section{Introduction}

The biopsychosocial (BPS) perspective on health, based on the International Classification of Functioning, Disability, and Health (ICF) ${ }^{1}$, enables the child development to be understood as complex and multifactorial. This agrees with the current theories, supported by the contextual/ecological theoretical model, in which such development depends on the individual's relations with the environment and with the task/stimuli received ${ }^{2}$.

Although the ICF is broadly used as an epidemiologic tool in health and follow-up of actions in the context of community health, it is considered a classification instrument, and studies are presently being undertaken for it to be applied in health interventions. Regarding child health, the study by Araujo et al. ${ }^{3}$ systematized this instrument with contextual factors of the children's health, such as family environment, stimuli received and motor development.
When considering child health, Early Intervention Programs (EIP) have been broadly used as an assessment and intervention strategy on the early development stages of children at risk, with established risk ${ }^{4}$ and/or with atypical development ${ }^{5}$. Nonetheless, there are gaps concerning the parameters as to the type of intervention, intensity and time, besides limitations regarding the number of the sample, statistical power, and selection of instruments, which is due to the paucity of studies systematizing early practices with approaches that consider the development in its complexity of factors and structured based on the broadened perception of health through the $\mathrm{ICF}^{6}$.

Despite the diversity of intervention parameters, recent studies recommend family-centered and child-contextualized interventions ${ }^{7}$. It is necessary to consider the context to which the child belongs, and thus involve the families in child attention programs for better results and effects to be achieved ${ }^{8}$. The study by Jhonson ${ }^{9}$ shows that 
interventions with family training have a significant role in promoting development, in addition to improving the interaction between parents and children with developmental disorders, it is recommended by the World Health Organization (WHO) as the main intervention strategy for children ${ }^{10}$. Early family-centered interventions are efficient to improve motor, social, communicative, academic and selfhelp skills of the participating children ${ }^{9}$.

The Sociedade Brasileira de Pediatria ${ }^{11}$ (Brazilian Pediatrics Society) instructs that health professionals, family and school must adhere to promoting physical activities at an early age, when still two years old, regarding babies, these activities should be of at least $180 \mathrm{~min}$ utes throughout the day. As a consequence of the condition the families are found in and with the socioeconomic transformations in the society, babies spend a long time at the daycare centers, with periods extending up to 8 or 10 hours a day ${ }^{5}$. In the face of this situation, intervention programs for this population must involve the environments the child belong to, the family and the daycare.

In this regard, the aquatic activities are considered excellent intervention tools ${ }^{12}$ associating enriched environments with the family's active participation ${ }^{8}$. The aquatic environment (AE) brings benefits for babies on the social context, strengthens family ties and improves mobility, coordination and response speed, with repercussions on neuropsychomotor development (NPMD) ${ }^{13}$. Nevertheless, despite the wide usage of water as a resource in pediatric interventions, called aquatic physiotherapy (AP), the lack of evidence-based research is consensual in the literature, and the existing studies present low methodological quality, which makes the proof and efficiency of this therapeutic approach difficult ${ }^{14,15,13}$, thus justifying new studies aimed at a better investigation of the theme presented.

Therefore, this study aimed at describing an ICFbased aquatic early intervention program (KITE) for the NPMD of 4- to 18-month-old typical, at-risk and/or delayed babies. The study hypothesizes that the intervention program conducted in $\mathrm{AE}$, centered on the family and in the daycare environment, twice a week, throughout four weeks is sufficient to reverse the risk/delay and keep the baby in typical parameters.

\section{Methods}

\section{Study design}

The protocol for interventional clinical trials follows the guidelines of the Standard Protocol Items: Recommendations for Interventional Trials (SPIRIT) guidelines ${ }^{16}$.

The research was approved by the Research Ethics Committee of the Universidade Federal do Paraná (Federal University of Paraná - UFPR), under evaluation report no. 1.714.810, and Certificate of Presentation for Ethical Consideration (CAAE): 57193516.6.0000.0102, and filed at the Brazilian Registry of Clinical Trials (RBR) 2hd6sm. It is an EIP with aquatic activities, called KITE, to be performed with babies 4 to 18 months old who attend day care centers.

\section{Participants}

The inclusion criteria for participating in the study are: 4- to 18-month-old babies, of both genders, attending public or associated daycare centers, having been adapted to it for at least 15 days, having the parents' and/or guardians' permission through the Informed Consent Form, not participating in any EIP or aquatic stimulation, and that both the baby and the parent/guardian have a medical certificate attesting they are fit for aquatic activities.

For the first assessment, babies 4 to 16 months old, of both genders, will be screened through the Alberta Infant Motor Scale (AIMS) and the Denver Developmental Screening Test II (DDST-II) for neuropsychomotor assessment and screening, in order to identify whether the babies had typical development, or were at risk or delayed. The age of 4 months was considered for its being the minimum age for a baby to be accepted in a daycare center, as well as a safe age for AE; as for the maximum age of 16 months for the initial assessment, the two months taken for intervention and follow-up are taken into account, as up to 18 months it is possible to follow up with specific validated scales. The preterm babies ( $<37$ weeks) are assessed considering the recalculated age $\mathrm{e}^{17}$.

Typical babies are considered the ones presenting percentages $>25$ on AIMS and one caution at the most on DDST-II; at risk are the ones with percentages $>5$ and $<$ 25 on AIMS and up to one fail and one or two cautions on DDST-II; and, delayed, the babies with percentages $<5$ on AIMS and more than one fail and/or two or more cautions on DDST-II ${ }^{18,19}$.

The exclusion criteria consider the atypical babies, with musculoskeletal, neurological or sensorial alterations affecting the NPMD, as well as swimming pool-related contraindications. Although being excluded from the data analysis of the study, any baby in these conditions, as long as meeting the inclusion criteria, could participate in the interventions in an adapted way.

\section{Intervention and control group}

The assessments will be conducted at the daycare itself, and the interventions in a swimming pool adapted for babies. All the babies and their parents/guardians will be invited to participate in the KITE and, according to the interest and availability of the participants, the babies will be divided into a control group (CG) and an intervention group (IG). The IG participated in the KITE in the therapeutic pool, in a group, and the CG received no specific intervention. 
In order to favor the ecological validity of the study $^{20}$, the babies are assessed at the very daycare center with the teachers present. The interviews with the families will also be conducted in the daycare environment.

\section{Kids Intervention Therapy - Aquatic environment (KITE)}

The KITE has been developed for the target public of typical babies and/or at NPMD risk or delay, 4 to 18 months old, attending daycare centers, as systematized in Figure 1, according to the ICF-CY domains ${ }^{1}$. The triangle in the figure and the highlights in red represent the intervention program. The health condition is related to the NPMD classification as typical, risk or delay. The peculiarities of each body are understood through bodily functions and structures. The activities and participation encompass the functional movement in the water and its repercussions on the land; the activities are milestones according to each child's age group, and the participation is the baby's, family's or daycare center's involvement. The transfer to the environment and the family's participation make up the contextual factors; therefore, the environmental factors comprise the intervention program, the aquatic, home, and school environments; as for the baby's adaptation, it is considered in the domain of personal factors.
The KITE lasts 45 to 60 minutes to avoid the baby's fatigue $^{21}$, twice a week, for four weeks ${ }^{22}$. The activities of the KITE are directed by two physiotherapists (instructors) experienced in the field of in-water therapy, assisted in the water by two physiotherapy students, and another two outside the water for support, with the mother's, father's or guardian's active participation in the pool (conductors) in the process of stimulating their children. The therapies are performed in small groups, with 10 participants at the most. All activities are carried out in a ludic manner, with child songs and play related to their age group.

The KITE is described in detail in Table S1, which is organized according to Israel's five phases ${ }^{23}$, the movement axes, the functional goal, and expected motor behavior, the main effects of the immersed body, exercise progression parameter, transferring skills to the land, and mobility classification in the activity and participation domains of the ICF-CY. In Figure 2, the order of the activities is described by day of the intervention, their goals and the guidelines given for home.

The KITE is performed in a heated pool at $32{ }^{\circ} \mathrm{C}$, following Israel and Pardo's ${ }^{23}$ five phases adapted to the babies: (1) adaptation: going in and out of the pool, experiencing the physical properties of the water, warming up and moving around; (2) familiarization with the liquid

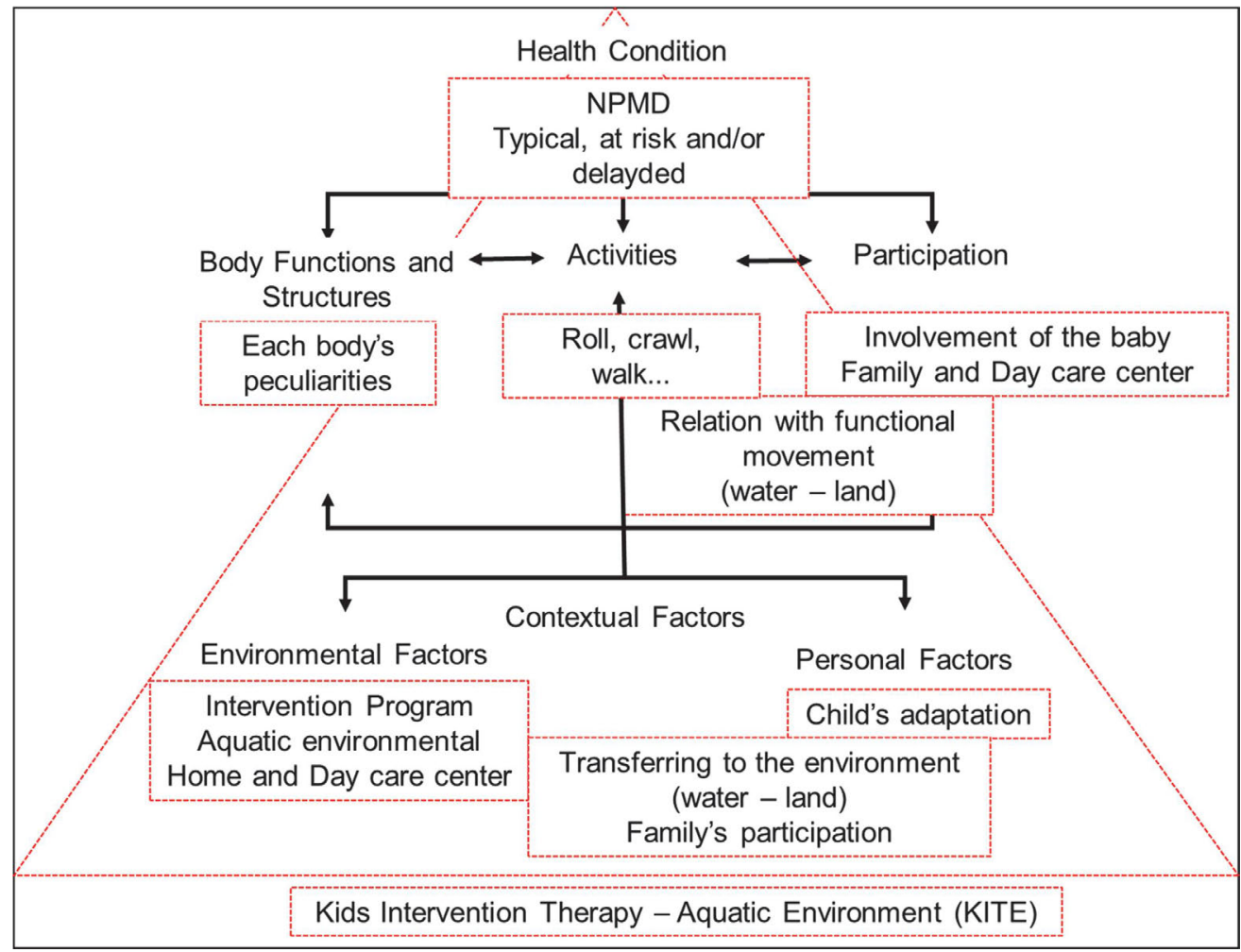

Figure 1 - Systematization of the kite according to the domains of the ICF. Source: Adapted from WHO ${ }^{1}$. Legend: NPMD - neuropsychomotor development. 


\begin{tabular}{|c|c|c|c|c|}
\hline Week & Intervention & Objective & $\begin{array}{l}\text { Motor Behaviors } \\
\text { Performed (Annex 1) }\end{array}$ & Guidelines performed \\
\hline \multirow{2}{*}{$1^{\text {st }}$ week } & 1 & \multirow{2}{*}{$\begin{array}{l}\text { Adaptation to the liquid } \\
\text { environment, social } \\
\text { interaction }\end{array}$} & $1,2,3,7,10,18,46,6$ & \multirow{2}{*}{$\begin{array}{l}\text { Stimulation in the daily } \\
\text { activities, bath, feeding, } \\
\text { change, displacement. Visual } \\
\text { contact and talk with the } \\
\text { baby. }\end{array}$} \\
\hline & 2 & & $1,2,5,8,11,19,35,22,6$ & \\
\hline \multirow{2}{*}{$2^{\text {nd }}$ week } & 3 & \multirow{2}{*}{$\begin{array}{l}\text { Experiencing and } \\
\text { stimulating the areas of } \\
\text { gross motor, fine motor } \\
\text { and language }\end{array}$} & $1,2,9,12,13,27,45,23,6$ & \multirow{2}{*}{$\begin{array}{l}\text { Playing to stimulate. } \\
\text { Different postures with visual } \\
\text { and sound stimuli. Different } \\
\text { stimuli. Singing to the baby. }\end{array}$} \\
\hline & 4 & & $1,2,14,28,36,30,24,6$ & \\
\hline \multirow{2}{*}{$3^{\text {rd }}$ week } & 5 & \multirow{2}{*}{$\begin{array}{l}\text { Improvement of the motor } \\
\text { acquisitions }\end{array}$} & $1,2,15,21,29,37,43,25,6$ & \multirow{2}{*}{$\begin{array}{l}\text { Playing to stimulate. } \\
\text { Exploring the floor and } \\
\text { singing different songs to the } \\
\text { baby. }\end{array}$} \\
\hline & 6 & & $1,2,31,38,39,40,44,6$ & \\
\hline \multirow{2}{*}{$4^{\text {th }}$ week } & 7 & \multirow{2}{*}{$\begin{array}{l}\text { Learning of the motor } \\
\text { acquisitions }\end{array}$} & $1,2,16,32,26,41,42,6$ & \multirow{2}{*}{$\begin{array}{l}\text { Playing to stimulate. } \\
\text { Changing the stimulus } \\
\text { environment. Telling stories } \\
\text { to the baby. }\end{array}$} \\
\hline & 8 & & $1,2,4,17,19,33,34,26,6$ & \\
\hline
\end{tabular}

Figure 2 - Organization of the objectives of the kite and guidelines for home.

environment: rotation, straightening and balance stimuli; (3) relaxation: return to quietness; (4) specialized therapeutic exercises: NPMD milestones stimuli; (5) global organic conditioning: active and free moving.

To standardize and systematize the KITE, the activities are developed according to specific functional goals and motor behaviors expected for each age group in three main axes: locomotor, stabilizer and manipulative ${ }^{24,25}$.

The locomotor activities involve displacement in accordance with the NPMD stage, growing more and more difficult as the physical properties of the water and the variance of movement and amplitude, weight/strength, speed, space and time parameters are incremented. The stabilizer ones involve activities in stable positions supported by the water, as in the progression of the movement parameters develop to unstable positions, using the turbulence of the water to aggravate stability. The manipulative activities have the objective of catching, manipulating, releasing, fitting, playing with and pushing various objects of contrasting sizes, shapes, weights, textures, dimensions and densities. These are also used as the phase of returning to quietness and concentration. All the activities approach the combined use of language stimulation through child songs.

Throughout the four weeks of the KITE, the activities follow weekly progression criteria, as the execution of the exercises grows more difficult according to the physical properties of the water: in the first week, the water is used to facilitate the movements; in the second week, it is used as a stabilizer; in the third week, as resistance to the movements; and in the fourth week, resistance is increased by the speed of the movements. Furthermore, the contact surface is changed in the following order: firm surface, soft/unstable surface, surfaces of different textures, and inclined surface ${ }^{25}$. The KITE uses low-cost material, previously selected by the researchers to standardize the intervention.

Individual evolution records are made daily for each family participating in the KITE on a field journal. These entries include the execution and quality of the movement in each activity proposed, evolution parameters for each child, family involvement, daily reports of the participants regarding the baby's performance and daily changes observed outside the AE.

In addition to participating in the KITE, the parents/ guardians of the IG babies received a weekly folder with ludic stimulation tips, totaling four guidance blocks. This guidance is in line with the KITE's weekly goals, described in Figure 2. To control this home stimulation and the stimulation tips, the Affordances in the Home Environment for Motor Development - Infant Scale (AHEMD-IS) was used in the three assessment moments.

\section{Blinding}

For the blinding of the study, the assessor does not know which baby will participate in the KITE's IG and which in the CG, and assesses all the 4- to 18-month-old babies and interviews all the parents/guardians without knowing which group they belong to. For this purpose, a second assessor (the KITE instructor) will schedule all the assessments and instruct the family not to report to the assessor about the group they belong to.

\section{Adverse outcomes}

All the activities will be performed by professionals experienced with babies, to avoid incidents, besides following the ethical guidelines regarding research with 
humans, water safety, and the use of safe and KITE-adapted settings and material.

In the case the need for diagnostic investigation or specific interventions are observed, both in the CG and in the IG, the parents/guardians will be instructed and referred to the closest healthcare unit.

\section{Recruiting}

Recruiting is initially conducted via the Municipality Department of Education (MDE), which indicates daycare centers for participation. Then, contact is made with the school's principal for the project to be approved. Following approval, the daycare's nursery teachers are instructed regarding the research, and in the sequence, an appointment with the parents/teachers in the daycare center will be scheduled for orientation as well as an invitation for them to participate, which is sent in the child's diary. After the parents'/guardians' reply, an initial interview is scheduled, and only then the babies begin to be assessed. In this interview, the objectives of the study are explained, as well as its stages, and the rights of the participants in the research. A written Informed Consent Form is required, and, depending on interest and availability, the child is allocated in the groups of the study.

\section{Assessments}

The assessments are systematized according to the BPS model of the $\mathrm{ICF}^{26}$ and aim at characterizing the sample \{anamnesis, health booklet and socioeconomic questionnaire of the Associação Brasileira de Empresas de Pesquisa para o Brasil - ABEP (Brazilian Association of Research Companies for Brazil)\} and answering the primary and secondary outcomes. Their systematization is described in the study by Mélo et al. ${ }^{26}$. For this study, three assessment measurements are conducted: assessment 1 (pre-intervention), assessment 2 (post-intervention), and assessment 3 (retention/follow-up).

\section{Primary outcomes}

The primary outcome is the verification of the effect of the KITE on the NPMD of 4- to 18-month-old babies. For such, the babies will be assessed at three moments, using AIMS and the DDST-II.

AIMS $^{27,18}$ assesses the NPMD through observation of the baby's spontaneous movements, alignment and contact surface in four postures (prone, supine, sitting and standing). In the end, the scores in each posture observed are added up in a total score of the items observed, being related to age and to the baby's score for their percentage to be defined ${ }^{18}$.

The DDST-II is a NPMD screening instrument that assesses the gross motor, adaptive fine motor, personalsocial, and language domains through the observation of items specific to the age assessed, in each area/domain of the scale, and enables the child's development to be characterized as typical, at-risk or delayed ${ }^{28,29}$.

\section{Secondary outcomes}

The secondary outcomes are the verifications of the effect of the KITE on the quality of life (QoL), stimulation received and aquatic skill. These assessments are conducted at three moments through the Pediatric Inventory on the babies' QoL (PedsQL ${ }^{\mathrm{TM}}$ ), Affordances in the Home Environment for Motor Development - Infant Scale (AHEMD-IS), and Aquatic Functional Assessment Scale - Baby (AFAS Baby), respectively.

For QoL outcome, the babies' PedsQLTM, 1-12 months and 13-24 versions are used, through interviews with parents and/or caregivers ${ }^{30}$. The AHEMD-IS is used to investigate the stimulation received in the home environment $^{31}$, for both quali- and quantitative verification of the motor enrichment opportunities, in the home environment, related to the variety of stimulation, physical space, global motricity toys, and fine motricity toys. The aquatic motor skills are assessed through the AFAS Baby, an adaptation for infants of the AFAS scale ${ }^{32}$, which is in the validation process.

\section{Sample calculation}

For the sample calculation, the number of children 0 to 4 years old was considered to be approximately $107,000^{33}$, with an estimated total of 50,000 children in day care/school (Curitiba, Paraná - MDE). Despite there being great variation in the estimates on NPMD delay, an average was considered according to its situation in Brazil and in municipal daycare centers, as well as to the pilot study conducted in the context of this study ${ }^{4}$, resulting in approximately $30 \%{ }^{34}$ of babies being at-risk/delayed in NPMD.

Once set the effect size of 0.25 , type I error 0.05 , analysis power of 0.95 in a proportion of 3:1 of typical children in relation to those at-risk, according to calculations performed on the $\mathrm{G} *$ Power 3.1.9.2 program, as well as the three assessment measurements to be conducted, 44 babies are necessary for the study. It is important to highlight that the sample calculation must be adapted according to the situation in the place where the study is made.

\section{Statistical analysis}

In the phase of describing the data collected, descriptive measurements will be calculated for the quantitative variables: averages, sample size, standard deviation, minimum and maximum. For the qualitative variables, tables will be created, in which the frequency of answers will be summarized.

For the analyses, the software will be the Statistica version 7 and the SPSS version 20. For the comparison between groups, the chi-squared test (or Fisher's test) is applied to categorical variables, and Student's $t$-test, to the 
quantitative variables with a normal distribution. As for the quantitative variables without normal distribution, the Mann-Whitney nonparametric test is applied. For the comparison between the pre-intervention, post-intervention and retention moments, the McNemar test is applied to the categorical variables, and the Friedman test, to the quantitative variables. To assess the effect size, the $\eta^{2}$ (etasquared) coefficient and Cohen's $d$ coefficient are calculated. Attention is called to the need of adapting the statistical tests according to the distribution of collected data. Another test option is the generalized estimating equation (GEE), although it requires sufficiently large samples to be used.

\section{Discussion}

This clinical trial description enables an aquatic intervention program, called KITE, to be applied in a systematic and controlled fashion. It fills in the gaps in the literature regarding parameters of type, intensity and time, in addition to being based on the current development theories and structured in accordance with the broadened perspective of health through the ICF.

For many years, the early intervention had been focused on bodily functions and structures, without repercussions on the child's activity and participation. With the BPS look proposed by the ICF model, these interventions are seeking strategies to improve activity with repercussions on the child's participation through the involvement of personal, family, contextual and environmental factors $^{35}$.

The discussion in this study is structured on the 10 principles of experience-debate neuroplasticity, described in the study by Kleim and Jones ${ }^{36}$ and adapted to pediatric interventions by Spittle and Morgan ${ }^{35}$.

The principles are, use it or lose it, use it and improve it, specificity, repetition matters, intensity matters, time matters, salience matters, age matters, transference and interference. Despite these concepts being widely explained in the literature, there are gaps related to time, duration, frequency and intensity of these stimuli to the small child ${ }^{6,4}$ when referring to the EIP.

Use it or lose it. The first years of life, from the perspective of brain circuitry, are extremely relevant since the neural connection process is intense. However, it is important to emphasize that it is around the first year of life that a great pruning of unused neurons takes place ${ }^{37}$, which justifies the need for diversified stimuli in the baby's routine.

Use it and improve it. The practice with variability and repetition makes motor skills and learning happen ${ }^{38}$, so the child needs to observe and practice. This is due to the adequate quality intervention, favoring the reorganization of the nervous system, which is dynamic and adaptable to the environment and the stimulation ${ }^{39}$. As for group activities, they can activate mirror neuron circuits and favor motor learning ${ }^{40}$.

Specificity. Training must be specific to the motor gesture whose improvement is desired ${ }^{42}$. The baby needs the opportunities to have experiences, as their nervous system is sensitive to the stimuli and dependent on experiences. These, when offered with quality, form the basis for the brain structures and create new and fast neuron connections ${ }^{40,42}$.

Repetition matters. Learning depends on repetition to be retained; the same movement needs to be repeated in different ways, through the performance of specific tasks or abilities since neuroplasticity is learning-dependent or activity-dependent ${ }^{41}$. The continuous repetition in the baby's routine must be planned through home programs and family-centered guidelines ${ }^{8}$.

Intensity matters. Neuroplasticity depends on adequate intensity; the child must move even if for short periods, many times a day, totaling 180 minutes of activities fractioned throughout the day ${ }^{11}$. It is worth considering that interventions guided by professionals have repercussions on the NPMD when performed twice a week ${ }^{4}$.

Time matters. Intervention must take place early, as a means of optimizing the neural networks that take place intensely in the first years of life. Therefore, the use of different moments for stimulation is recommended, associated with the baby's routine, with enriched environments and experience opportunities ${ }^{40}$.

Salience matters. The ludic, pleasant interventions, based on the child's preferences and adequate to the age group and its peculiarities, are factors that must be taken into consideration in pediatric interventions ${ }^{43}$.

The $\mathrm{AE}$ is a therapeutic modality that, in addition to the widely known benefits to functioning and NPMD caused by the effects on the immersed body, stands out for being ludic and pleasant, which justifies EIP in this environment ${ }^{13}$.

Age matters. It is valuable to make good use of the first years of the baby's development since it is in this phase that most of the synapses take place; this makes this period more malleable for interventions ${ }^{37}$.

Transference. Through play, the child transfers what they have learned to life, accompanied by the sensorial information, be it tactile, visual, auditory, and/or perceptive. They function as feedback to mold the movement and plan its performance, with benefits for the quality of the movement, and repercussions on motor, cognitive, affective, sensorial and social development ${ }^{44}$.

The aquatic activity is peculiar due to its hydrodynamic and thermal properties, and in babies, it has repercussions on the cognitive, sensorial and motor areas. In addition, they bring a sense of freedom, memories of the mother's womb and motor memory of an aquatic experience, which enables the collection to be transferred to lifelong development ${ }^{45,13}$. 
Interference. The pleasant experience with adequate stimuli, love and care act as a neuroprotective factor, and will have positive repercussions on the NPMD. Moreover, in the long term, it will have an impact on their school and adult life, the same way that the lack of opportunities can limit the development of brain structures and these connections fundamental to the full development ${ }^{42,46}$.

When considering the systemic and multifactorial nature of the $\mathrm{NPMD}^{34}$, the use of adequate instruments systematized by the $\mathrm{ICF}^{3}$ enables intervention programs to be planned. Thus, the sensitive periods are optimized with theoretical bases ${ }^{4}$ in accordance with the local situation, different contexts and the BPS factors that influence the development process ${ }^{25,47}$.

\section{Conclusion}

This study has presented tools to apply a clinical trial through an early intervention program with aquatic activities (KITE) on the NPMD of 4- to 18-month-old, typical, at-risk and/or delayed babies. It was systematized according to the intervention parameters, based on the ICF's BPS perspective applied to intervention, and discussed according to the neuroplastic evidence of child development.

\section{Acknowlegdments}

Financial support: This study was financed in part by the Coordination for the Improvement of Higher Education Personnel (Coordenação de Aperfeiçoamento de Pessoal de Nível Superior - CAPES - Brazil) - Finance Code 001 .

1. Organização Mundial da Saúde (OMS). Classificação Internacional de Funcionalidade, Incapacidade e Saúde (CIF). São Paulo: EDUSP, 2015. ISBN 10: 8531407842.

2. Hwang AW, Liao HF, Chen PC, Hsieh WS, Simeonsson RJ, Weng LJ, et al. Applying the ICF-CY framework to examine biological and environmental factors in early childhood development. J Formos Med Assoc. 2014;113(5):303-12. doi: 10.1016/j.jfma.2011.10.004.

3. Araujo LB, Novakoski KRM, Bastos MSC, Mélo TR, Israel VL. Caracterização do desenvolvimento neuropsicomotor de crianças até três anos: o modelo da CIF no contexto do NASF. Cad Bras Ter Ocup. 2018;26(3):538-557. doi: 10.4322/2526-8910.ctoAO1183.

4. Mélo TR, Araujo LB, Ferreira MP, Israel VL. Effects of an early intervention program by the ICF model on the neuropsychomotor development and quality of life in babies in daycare. Early child dev care. 2019;1-13. doi: 10.1080/ 03004430.2019 .1691545$.

5. Guimarães FAB, Assis CD, Vieira MEB, Formiga CKMR. Avaliação de material didático elaborado para orientação de cuidadores e professores de creches sobre o desenvolvimento infantil. Rev Bras Crescimento Desenvolv Hum. 2015;25(1):27-40. doi: 10.7322/JHGD.96764.
6. Tremblay MS, LeBlanc AG, Carson V, Choquette L, Connor Gorber S, Dillman C, et al. Canadian physical activity guidelines for the early years (aged $0-4$ years). Appl Physiol Nutr Metab. 2012;37(2):345-356. doi: 10.1139/h2012018.

7. Spittle A, Orton J, Anderson PJ, Boyd R, Doyle LW. Early developmental intervention programmes provided post hospital discharge to prevent motor and cognitive impairment in preterm infants. Cochrane Database Syst Rev. 2015;24 (11):CD005495. doi: 10.1002/14651858.CD005495.

8. Rosenbaum, P. Family and quality of life: key elements in intervention in children with cerebral palsy. Dev Med Child Neurol. 2011;53(4):68-70. doi: 10.1111/j.14698749.2011.04068.x.

9. Johnson, B. Developmental Disorders in Children - Importance of Parent Training Interventions. BMH Med J. 2018;5 (1):27-31. ISSN 2348-392X. Available from: https://www. babymhospital.org/BMH_MJ/index.php/BMHMJ/article/ view/160.

10. Hamdani SU, Akhtar P, Zill-E-Huma, Nazir H, Minhas FA, Sikander S. et al. WHO Parents Skills Training (PST) programme for children with developmental disorders and delays delivered by Family Volunteers in rural Pakistan: study protocol for effectiveness implementation hybrid cluster randomized controlled trial. Glob Ment Health. 2017;4(11):1-11. doi: 10.1017/gmh.2017.7.

11. Barros RR, Silva LR, Quadros TMB, Gordia AP, Mota J, Barros MVG, et al. Manual de Orientação: Grupo de Trabalho em Atividade Física. Promoção da Atividade Física na Infância e Adolescência. Sociedade Brasileira de Pediatria, 2017;1. Available from: http://www.sbp.com.br/filead min/user_upload/19890e-MO-Promo_AtivFisica_na_In f_e_Adoles-2.pdf. [Acessed 19th nov 2019].

12. Araujo LB, Silva TC, Oliveira LC, Tomasetto LC, Kanashiro MS, Braga DM. Efeitos da fisioterapia aquática na função motora de indivíduos com paralisia cerebral: ensaio clínico randomizado. Fisioter Bras. 2018;19(5):613-23. doi: 10.33233/fb.v19i5.2149.

13. García JL, López AMS, García LB, Segovia JPN, Cordero MJA. Influencia de la actividad física acuática sobre el neurodesarrollo de los bebés: revisión sistemática. Nutr Hosp. 2016;33(5):10-17. doi: 10.20960/nh.515.

14. Getz M, Hutzler Y, Vermeer A. Effects of aquatic interventions in children with neuromotor impairments: a systematic review of the literature. Clin Rehabil. 2006;20(11):927-936. doi: $10.1177 / 0269215506070693$.

15. Jacques KC, Drumond NR, Andrade SAF, Chaves Júnior IP, Toffol WC. Effectiveness of the hydrotherapy in children with chronic encephalopathy no progressive of the childhood: a systematic review. Fisioter Mov. 2010;23(1):53-61. doi: 10.1590/S0103-51502010000100005.

16. Chan A-W, Tetzlaff JM, Gøtzsche PC, Altman DG, Mann H, Berlin JA, et al. SPIRIT 2013 explanation and elaboration: guidance for protocols of clinical trials. Bmj. 2013;346:e7586. doi: 10.1136/bmj.e7586.

17. Araujo LB. Análise do desenvolvimento neuropsicomotor de crianças de zero a três anos em centros de educação infantil. Curitiba. Dissertação [Mestrado em Educação Física]. Universidade Federal do Paraná; 2013. 
18. Saccani R, Valentini NC, Pereira KR. New Brazilian developmental curves and reference values for the Alberta infant motor scale. Infant Behav Dev. 2016;45:38-46. doi: 10.1016/j.infbeh.2016.09.002.

19. Drachler ML, Marshall T, De Carvalho Leite JC. A continuous-scale measure of child development for populationbased epidemiological surveys: a preliminary study using Item Response Theory for the Denver Test. Paediatr Perinat Epidemiol. 2007;21(2):138-53. doi: 10.1111/j.13653016.2007.00787.x.

20. Gerzson LR, Catarino BM, Azevedo, KA, Demarco PR, Palma MS, Almeida CS. Frequência semanal de um programa de intervenção motora para bebês de berçário. Fisioter Pesqui. 2016;23(2):178-84. doi: 10.1590/1809-2950/ 14923223022016 .

21. McManus BM, Kotelchuck M. The effect of aquatic therapy on functional mobility of infants and toddlers in early intervention. Pediatr Phys Ther. 2007;19(4):275-282. doi: 10.1097/PEP.0b013e3181575190.

22. Gorter J, Currie S. Aquatic exercise programs for children and adolescents with cerebral palsy: what do we know and where do we go? Int J Pediatr. 2011;2011(712165):1-7. doi: $10.1155 / 2011 / 712165$.

23. Israel VL, Pardo MBL. Hidroterapia: proposta de um programa de ensino no trabalho com o lesado medular em piscina térmica. Fisioter Mov. 2000;13(1):111-7. ISSN 19805918.

24. Bertoldi ALS, Israel VL, Ladewig I. Efeitos da atenção dirigida para parâmetros da qualidade de movimento na recuperação neurofuncional: relato de caso. Fisioter Mov. 2008;21(3):19-25. Available from: https://periodicos.pucpr. br/index.php/fisio/article/view/19129/18473. [Acessed 19th nov 2019].

25. Mélo TR, Araujo LB, Yamaguchi B, Ferreira MP, Israel VL. Early intervention program by ICF model for babies of 4-18 months frequenting daycare center: protocol for clinical trial. Motriz: rev educ fis. 2019;25(3):e101945. doi: 10.1590/s1980-6574201900030019.

26. Mélo TR, Araujo LB, Novakoski KRM, Israel VL. Systematization of evaluation instruments for the two first years of life of typical or risk infants according to the ICF model. Fisioter Pesq. 2019;26(4):1-14. doi: 10.1590/1809-2950/ 18026126042019.

27. Darrah J, Bartlett D, Maguire TO, Avison WR, LacazeMasmonteil T. Have infant gross motor abilities changed in 20 years? A re-evaluation of the Alberta Infant Motor Scale normative values. Dev Med Child Neurol. 2014;56(9):87781. doi: 10.1111/dmen.12452.

28. Frankenburg WK, Dodds J, Archer P, Bresnick B, Maschka $\mathrm{P}$, Edelman N, et al. Manual de treinamento (Adaptação brasileira). In Sabatés AL (Ed.). Denver II Teste de Triagem do Desenvolvimento. São Paulo: Hogrefe, 2017. p.1-53. ISBN 9788585439569.

29. Frankenburg WK, Dodds J, Archer P, Bresnick B, Maschka $\mathrm{P}$, Edelman N, et al. Manual técnico (Adaptação brasileira). In: Sabatés AL, (Ed.). Denver II Teste de Triagem do Desenvolvimento. São Paulo: Hogrefe, 2018. p.1-48. ISBN 978-85-85439-60-6.

30. Varni JW, Limbers CA, Neighbors K, Schulz K, Lieu JE, Heffer RW, et al. The PedsQL\&\#x0099; Infant Scales: fea- sibility, internal consistency reliability, and validity in healthy and ill infants. Qual Life Res. 2011;20(1):45-55. doi: 10.1007/s11136-010-9730-5.

31. Caçola PM, Gabbard C, Montebelo MIL, Santos DCC. The new affordances in the home environment for motor development-infant scale (AHEMD-IS): Versions in English and Portuguese languages. Braz J Phys Ther. 2015;19(6):507525. doi: 10.1590/bjpt-rbf.2014.0112.

32. Israel VL, Pardo MBL. Hydrotherapy: Application of an Aquatic Functional Assessment Scale (AFAS) in Aquatic Motor Skills Learning. American International Journal of Contemporany Research. 2014;4(2):42-52. ISSN 2162$142 \mathrm{X}$.

33. IBGE - Instituto Brasileiro de Geografia e Estatística. 2010. Available from: http://www.censo2010.ibge.gov.br/. [Acessed 19th nov 2019].

34. Araujo LB, Mélo TR, Israel VL. Low birth weight, family income and paternal absence as risk factors in neuropsychomotor development. J Hum Growth Dev. 2017;27(3):27280. doi: $10.7322 /$ jhgd. 124072 .

35. Spittle AJ, Morgan C. Early Intervention for Children with Cerebral Palsy. In: Panteliadis C. (Eds) Cerebral Palsy. Springer, Cham; 2018. p.193-200. doi: 10.1007/978-3-31967858-0_18.

36. Kleim JA, Jones TA. Principles of experience-dependent neural plasticity: implications for rehabilitation after brain damage. J Speech Lang Hear Res. 2008;51(1):S225-S239. doi: 10.1044/1092-4388(2008/018).

37. Noer C, Halpern R. O pediatra e a promoção do desenvolvimento infantil: otimizando a consulta. Resid Pediatr. 2018;8 (3):156-162. doi: 10.25060/residpediatr-2018.v8n3-12.

38. Diedrichsen J, Kornysheva K. Motor skill learning between selection and execution. Trends Cogn Sci. 2015;19(4):22733. doi: 10.1016/j.tics.2015.02.003.

39. Cramer SC, Sur M, Dobkin BH, O'Brien C, Sanger TD, Trojanowski JQ, Rumsey JM, et al. Harnessing neuroplasticity for clinical applications. Brain. 2011;134(6):15911609. doi: 10.1093/brain/awr039.

40. Cioni G, Inguaggiato E, Sgandurra G. Early intervention in neurodevelopmental disorders: underlying neural mechanisms. Dev Med Child Neurol. 2016;58(4):61-6. doi: 10.1111/dmcn.13050.

41. Borella MP, Sacchelli T. Os efeitos da prática de atividades motoras sobre a neuroplasticidade. Revista de Neurociências, v. 17, n. 2, p. 161-169, 2009. ISSN 0104-3579.

42. UNICEF. United Nations Children's Fund. Early Moments Matter for Every Child. UNICEF: September, 2017. p. 88. ISBN: 978-92-806-4901-7.

43. Rosenbaum P, Gorter JW. The 'F-words' in childhood disability: I swear this is how we should think! Child Care Health Dev. 2011;38(4):457-463. doi: 10.1111/j.13652214.2011.01338.x.

44. Araujo LB, Israel VL. (Ed.). Desenvolvimento da criança: família, saúde e escola. Curitiba: Omnipax, 2017. ISBN 978-85-64619-19-7. doi: 10.7436/2017.dcfes.0.

45. Israel VL. Hidroterapia com bebês especiais: um caminho diferente. In: Bolsanello MA (Org.). I Simpósio Nacional de Atenção e Estimulação Precoce. Laboratório de Estimulação e Atenção Precoce de bebês (LABEBÊ). Atenção e 
Estimulação Precoce: bebês com deficiência. 110 f. 1 ed. Curitiba: Universidade Federal do Paraná, 2008.

46. Chan M, Lake A, Hansen K. The early years: silent emergency or unique opportunity? The Lancet. 2017;389 (10064):11-13. doi: 10.1016/S0140-6736(16)31701-9.

47. Mélo TR, Araujo LB, Yamaguchi B, Ferreira MdP, Israel VL. Quality of life and neuropsychomotor development of infants 4-18 months in daycare center. Cien Saude Colet. 2018. Available from: http://www.cienciaesaudecoletiva. com.br/artigos/quality-of-life-and-neuropsychomotordevelopment-of-infants-between-418-months-in-daycarecenter/16998?id=16998. [Acessed 19th nov 2019].

\section{Supplementary Material}

The following online material is available for this article:

Table S1: Kids Intervention Therapy - Aquatic Environment (KITE).

\section{Corresponding author}

Luize Bueno de Araujo: Avenida Cândido de Abreu, 347. Apto 1204. Centro Cívico. 80530-000. Curitiba/PR, Brasil.

E-mail: luizebueno@hotmail.com.

Manuscript received on December 9, 2019

Manuscript accepted on March 17, 2020

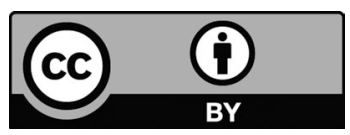

Motriz. The Journal of Physical Education. UNESP. Rio Claro, SP, Brazil - eISSN: 1980-6574 - under a license Creative Commons - Version 4.0 